\title{
ALCOHOL AND DRUGS IN POST-WAR SIERRA LEONE
}

\section{Morten Bøås, * Anne Hatløy and Ingunn Bjørkhaug}

\author{
Fafo Institute for Applied International Studies
}

Oslo, Sweden

\begin{abstract}
The kind of social stress that a civil war expose the population to makes it easy to assume that an increased level of alcohol and drug abuse should be observable in post-war Sierra Leone. This is, however, not the case. As this study reveals, the pattern of alcohol and drug consumption in Sierra Leone is the same as we find in other African countries that has never experienced civil war. The majority of the population do not drink very much or use drugs at all, but there is a small minority that are frequent drinkers and use drugs. These findings are based on a survey in Sierra Leone and explore who the drinkers are, how many people drink and what characterises drug users in Sierra Leone.
\end{abstract}

KeY Words: alcohol, drugs, Sierra Leone, war

\section{INTRODUCTION}

\section{Alcohol, drugs and civil war}

The civil war (1991-2002) in Sierra Leone is widely known for its brutality and the suffering it inflicted on the civilian population (Richards 1996; Abdullah 1998; Keen 2005; Bøås and Hatløy 2006; Bøås 2007). Alcohol and drugs played a part in the war as rebels, militia members and soldiers consumed it not only to boost their morale, but also as a tranquilliser to cope with the consequences of the human rights abuses that they committed (Amnesty International 1995; Musah 2000; Bangura 2004; Keen 2005). The kind of extreme social stress that a civil war such as this exposes the population to may also result in an increase in the general consumption of alcohol and drugs as well (Horton 1943; Mandelbaum 1963; Anderson and Mitchell 1992; Martin, Roman and Blum 1996); thus, making it easy to assume that an increased level of alcohol and drug abuse should be observable in post-war Sierra Leone.

Traditional alcohol in the form of palm wine - usually referred to as 'from God to Man' - has been consumed in Sierra Leone for centuries. Other forms of alcohol were introduced during the colonial period. Drugs, however, are a much more recent phenomenon (Abdullah 1998).

The difference between drinkers and nondrinkers is the simplest and most fundamental expression of difference in people's relationship

\footnotetext{
* Corresponding author: Morten Bøås, PhD, Senior Researcher, Fafo Institute for Applied International Studies, Oslo, Sweden. Tel: +47 22088610; E-mail morten.boas@fafo.no. Comments from two anonymous reviewers are highly appreciated.
} 
Table 1. Overview of the sample

\begin{tabular}{|c|c|c|c|c|c|}
\hline Sample & Freetown & Yoni & & & \\
\hline Description & Urban & Rural & Urban & Rural & Total \\
\hline Clusters & 11 & 4 & 4 & 6 & 25 \\
\hline Households & 189 & 70 & 56 & 114 & 429 \\
\hline Male & 169 & 65 & 50 & 103 & 387 \\
\hline Female & 173 & 67 & 52 & 99 & 391 \\
\hline Total Adults & 342 & 132 & 102 & 202 & 778 \\
\hline
\end{tabular}

to alcohol (Partanen 1988). The ratio of drinkers to non-drinkers, and their distribution among the Sierra Leone population, is most indicative of how alcohol is viewed in this society. In African societies, women drink less than men, and the number of women who do not drink at all are consistently higher than among men. Social sanctions against women drinking too much - or drinking at all - are widespread (Bryceson 2002). In most African societies, there is traditionally a significant contrast between drinkers and teetotallers. By and large, African societies tend to be quite sober, but most also have a smaller segment of the population that drinks quite substantially. The main objective of this article is therefore to gain a better understanding of the characteristics of drinkers, non-drinkers, and drug users in Sierra Leone. The study explores who the drinkers are, how many people drink and what characterises drug users in Sierra Leone. The latter issue is mainly explored by reference to our ethnographic material, as it is almost impossible to get reliable data about drug consumption in a quantitative survey.

\section{METHODS}

The method used for this study is a quantitative survey in combination with qualitative interviews, each complementing the other. The fieldwork was conducted in Freetown, in rural communities surrounding Mile 91 (in Yoni chiefdom in Tonkolili district) and in urban and rural communities in Bo (in Kakua, Tikonko, and Baoma Chiefdom). ${ }^{1}$

\section{Quantitative method}

Random sampling method was used for the quantitative method. The sampling frame was based on the Statistical Office in Sierra Leone's Master Sample. 25 clusters were drawn: 11 clusters in Freetown were randomly selected, all 4 clusters in Yoni Chiefdom in Tonkolili District were included, and, in Bo District, the clusters from Kakua (urban and rural), Tikonko (rural), and Baoma (rural). Chiefdoms were included. In each cluster, one location was randomly selected. Each cluster was mapped and listed in one day, and the field workers made appointments with the selected households for an interview the following day.

The sample is representative of the areas studied, but it does not represent the whole country. However, the sample is of a sufficient size to give a good indication of the situation in Sierra Leone. However, the reader should keep in mind that limitation to the study is that alcohol and drug use are sensitive issues and certain amount of under-reporting may have taken place.

\section{Qualitative method}

Qualitative interviews were implemented through ethnographic life history methodology and in focus group sessions. Many of the participants in this part of the study had personal war-time experiences. The contours of the history and legacy of the Sierra Leone civil war are important factors for gaining a better understanding of the alcohol and drugs situation in the country, and the qualitative interviews provided useful information that complimented the quantitative findings.

${ }^{1}$ The fieldwork was conducted in October 2004 (Bøås and Hatløy, 2005). 
Table 2. Socio-demographic background variables by gender in percent

\begin{tabular}{|c|c|c|c|c|}
\hline Characteristics & Male & Female & Total & $\mathrm{n}$ \\
\hline \multicolumn{5}{|l|}{ Age groups } \\
\hline $15-24$ years & 29 & 30 & 30 & 230 \\
\hline $35-39$ years & 38 & 43 & 41 & 315 \\
\hline $40-87$ years & 34 & 26 & 30 & 233 \\
\hline \multicolumn{5}{|l|}{ Marital status } \\
\hline Single & 35 & 20 & 20 & 213 \\
\hline Married & 62 & 70 & 70 & 509 \\
\hline Widowed, divorced, separated & 3 & 10 & 10 & 52 \\
\hline \multicolumn{5}{|l|}{ Ethnic groups } \\
\hline Mende & 31 & 34 & 32 & 253 \\
\hline Temne & 35 & 33 & 34 & 262 \\
\hline Other & 43 & 33 & 34 & 263 \\
\hline \multicolumn{5}{|l|}{ Religion } \\
\hline Muslim & 71 & 72 & 71 & 554 \\
\hline Christian & 28 & 28 & 28 & 218 \\
\hline Other & 1 & 0.5 & 1 & 6 \\
\hline \multicolumn{5}{|l|}{ Education } \\
\hline Never attended school & 35 & 51 & 43 & 330 \\
\hline Not completed primary & 10 & 15 & 12 & 96 \\
\hline Primary completed & 15 & 10 & 12 & 94 \\
\hline Junior secondary completed & 22 & 11 & 16 & 125 \\
\hline Senior secondary completed & 11 & 9 & 10 & 77 \\
\hline Higher education & 8 & 5 & 7 & 50 \\
\hline \multicolumn{5}{|l|}{ Employment (last month) } \\
\hline None & 18 & 21 & 20 & 152 \\
\hline Unpaid activities & 19 & 28 & 23 & 182 \\
\hline Self employed & 42 & 43 & 42 & 328 \\
\hline Paid employment/activities & 21 & 9 & 15 & 116 \\
\hline n & 387 & 391 & 778 & \\
\hline
\end{tabular}

In the individual 'life history' interviews and focus group sessions, the point of departure was the informants' location where the session was taking place. In other words, the actual physical site of the interview provided the starting point, and from this site the interviewer and informants tracked the life of the informants backwards. The aim was to establish the chain of events that led the informant(s) to the particular place where the session was taking place. In this process, the informants own perceptions of alcohol and drug use were an important subject for conversation and discussion. These informants were not randomly selected, but were chosen because they were underemployed youths, former combatants, hard drug users, and people spending most of their days in informal drinking places (where drugs were also used) in urban and semi-urban localities. Interviews were conducted with alcohol and drugs suppliers in these study areas as well.

\section{Fieldworkers}

Six experienced fieldworkers were employed to assist in the fieldwork. They were seconded from the Statistical Office in Sierra Leone. The fieldworkers were trained in mapping, 
Table 3. Alcohol consumption in percent by gender, age, and marital status

\begin{tabular}{|c|c|c|c|c|c|}
\hline \multirow[b]{2}{*}{ Characteristics } & \multicolumn{5}{|c|}{ Alcohol consumption $^{1}$} \\
\hline & $\begin{array}{l}\text { Never } \\
\mathrm{n}=549\end{array}$ & $\begin{array}{c}\begin{array}{c}\text { Former } \\
n=143\end{array} \\
\end{array}$ & $\begin{array}{c}\text { Current } \\
\mathrm{n}=86\end{array}$ & $\begin{array}{c}\text { Total } \\
\mathrm{n}=778\end{array}$ & $\mathrm{~N}$ \\
\hline \multicolumn{6}{|l|}{ Gender } \\
\hline Male & 66 & 20 & 14 & 100 & 387 \\
\hline Female & 78 & 16 & 6 & 100 & 391 \\
\hline \multicolumn{6}{|l|}{ Age } \\
\hline $15-24$ & 87 & 7 & 6 & 100 & 230 \\
\hline $25-39$ & 70 & 18 & 12 & 100 & 315 \\
\hline $40-87$ & 57 & 33 & 11 & 100 & 233 \\
\hline \multicolumn{6}{|l|}{ Marital status } \\
\hline Single & 80 & 8 & 12 & 100 & 213 \\
\hline Married & 69 & 21 & 9 & 100 & 509 \\
\hline $\begin{array}{l}\text { Widowed, } \\
\text { divorced, } \\
\text { separated }\end{array}$ & 59 & 36 & 5 & 100 & 52 \\
\hline Total & 72 & 18 & 10 & & 778 \\
\hline
\end{tabular}

${ }^{1}$ Never $=$ never tasted alcohol; former $=$ have tasted alcohol, but not consumed any during last 12 months; current $=$ have used alcohol during last 12 months.

listing and interviewing two days prior to the fieldwork. The questionnaire was in English, but the fieldworkers conducted the interviews in the local languages (e.g. Krio, Mende and Temne).

\section{Data analysis}

The questionnaire was developed by the authors of this article in collaboration with organisations working with alcohol and drug abuse in Sierra Leone. ${ }^{2}$ One person from the household selected who was 15 years or older was randomly chosen to answer the questions. The questionnaire consisted of 80 questions, where the first part dealt with socio-economic background variables (e.g. school attendance, income, religion) whereas the second part was concerned with the informant's relationship to alcohol and drugs (e.g. frequency of use, type of alcohol/drug, reasons for use of alcohol/ drugs). Fafo staff in Norway conducted the data entry, and CSPro version 2.6 was used to enter the questionnaires. The analysis was conducted in SPSS version 10.

\section{RESULTS}

A total of 778 people were interviewed and 50 percent of the respondents were males and 50 percent were females. The ethnic breakdown was 32 percent mende and 34 percent temne; the rest of the sample was a mix of other ethnic groups. The majority of the respondents were Muslims (71 percent) and Christians (28 percent). The sociodemographic characteristics of the sample size are described by gender in table 2 .

\section{Alcohol and drug use in Sierra Leone}

Drinking alcohol is not common in Sierra Leone. As shows, 72 percent of the population above 15 years of age claims that they have never tasted alcohol. ${ }^{3}$ Only one in ten claims to have tasted alcohol during the preceding year ('current user'), the remaining 18 percent have tasted alcohol, but not during the previous 12 months ('former user'). This corresponds quite well with the level of 'ever' users of alcohol found in a 2002 survey carried

${ }^{2}$ IOGT, Sierra Leone and FORUT Sierra Leone were consulted in this process.

${ }^{3}$ Tasted alcohol in this study was those who reported to have tasted alcohol once or more 
Table 4. Alcohol consumption in percent by residence

\begin{tabular}{llccccc}
\hline \multirow{2}{*}{$\begin{array}{l}\text { Areas of } \\
\text { residence }\end{array}$} & \multicolumn{7}{c}{ Alcohol consumption $^{1}$} & & & \\
\cline { 2 - 7 } & & Never & Former & Current & Total & N \\
\hline Freetown & Urban & 72 & 18 & 10 & 100 & 342 \\
Bo & Urban $^{2}$ & 80 & 17 & 3 & 100 & 102 \\
Bo & Rural $^{2}$ & 55 & 27 & 18 & 100 & 202 \\
Yoni & Rural & 85 & 9 & 6 & 100 & 132 \\
Total & & 72 & 18 & 10 & & 778 \\
\hline
\end{tabular}

${ }^{1}$ Never $=$ never tasted alcohol; former $=$ have tasted alcohol, but not consumed any during last 12 months; current $=$ have used alcohol during last 12 months

${ }^{2}$ Kakua, Baoma and Tikonko Chiefdom

out in Kambia (Northern region) and Kissy (Freetown) (Jensen 2002). In this study, 14 percent reported having ever used alcohol, and 5 percent claimed to drink daily.

Men are more likely to drink alcohol than women: 14 percent of men report drinking during the preceding year, as opposed to 6 percent of the women. Unsurprisingly, current users drink frequently - as many as 50 percent of men and 30 percent of women among current users claim to have drunk alcohol during the previous three days.

Younger people, considered to be those less than 25 years old, seem to drink more rarely than elder ones. Most 'former' users are found in the population above 40 years of age; the frequency of current users is approximately the same among this group and the group aged 25-39 years.

Marital status also seems to be linked to the consumption of alcohol. The highest frequency of current users is found among those who are single; this seems contradictory to the findings that young people drink less frequently than older people, as the 'single' as a group is younger than the majority of those married. However, this is explained by the fact that as many as 27 percent of the single respondents in the age group 25-39 are current users of alcohol, compared to only 9 percent of the married respondents in the same age group.

The prevalence of alcohol use in Sierra Leone is not just linked to personal characteristics like age, sex, and marital status. Table 4 shows a clear difference in the consumption patterns in the four sites where the survey was conducted. In the rural community around Bo, 18 percent are current users, while this is true of only 3 percent in the city of Bo.

In the rural villages in Yoni, the situation was similar to the low level in the city of Bo. Among the adult population in Freetown, the

Table 5. Alcohol consumers in percent by religious affiliation and ethnic group

\begin{tabular}{lccccc}
\hline & \multicolumn{5}{c}{ Alcohol consumption } \\
Characteristics & Never & Former & Current & Total & N \\
\cline { 2 - 6 } Religion & & & & & \\
Muslim & 79 & 15 & 6 & 100 & 554 \\
Christian & 53 & 28 & 19 & 100 & 218 \\
Ethnic group & & & & & \\
Mende & 65 & 21 & 14 & 100 & 253 \\
Temne & 82 & 13 & 6 & 100 & 262 \\
Other & 67 & 22 & 11 & 100 & 263 \\
Total & 72 & 18 & 10 & & 778 \\
\hline
\end{tabular}

${ }^{1}$ Never $=$ never tasted alcohol; former $=$ have tasted alcohol, but not consumed any during last 12 months; current = have used alcohol during last 12 months 
Table 6. Alcohol consumers in percent by educational level

\begin{tabular}{lccccc}
\hline \multirow{2}{*}{ Educational level } & \multicolumn{5}{c}{ Alcohol consumption } \\
\cline { 2 - 6 } & Never & Former & Current & All & N \\
\hline Never attended school & 74 & 19 & 6 & 100 & 330 \\
Not completed primary & 75 & 18 & 7 & 100 & 96 \\
Primary completed & 74 & 19 & 7 & 100 & 94 \\
Junior secondary completed & 73 & 20 & 7 & 100 & 125 \\
Senior secondary completed or & 62 & 14 & 24 & 100 & 127 \\
higher & 72 & 18 & 10 & & 772 \\
Total & & & & & \\
\hline
\end{tabular}

${ }^{1}$ Never $=$ never tasted alcohol; former $=$ have tasted alcohol, but not consumed any during last 12 months; current = have used alcohol during last 12 months

use was exactly the same as in the total survey population - that is, less prevalent than in Bo rural communities but more prevalent than in the city of Bo or in Yoni.

The differences between the rural areas in Bo and Yoni are significant. In Yoni, the population are mainly Temne, while the rural areas around Bo are mainly Mende.

Table 5 indicates that more Mende than Temne drink. The difference in consumption between the two ethnic groups nearly mirrors the difference between the rural areas in Yoni and Bo. Seventy percent of the respondents were Muslims as of which only 6 percent reported using alcohol the preceding year, compared with 19 percent of Christian respondents.

As many as 24 percent of the population with higher education - that is completed senior secondary school or some higher education - are current consumers of alcohol, as shown in Table 6. Our results show that it is approximately four times more likely for a person in the highest education bracket to drink alcohol than for someone with lower or no education.

Table 7 compare people's activity the previous month to their use of alcohol. Although the highest frequency of current users is found among those who had paid work the preceding month, the relationship between employment status and use of alcohol is not very clear. What are obvious, however, are the regional differences that also correspond to non-agricultural income-generating activities in rural areas. Thus, we now turn to our qualitative material to contextualise some of these findings.

\section{Cosmopolitan Freetown}

Two of the main sites for the qualitative fieldwork in Freetown were the areas known as 'Magazine' and 'Sawa Grounds'. 'Magazine' is a downtown area that lies between Nicols,

Table 7. Alcohol consumers in percent by activities reported last month

\begin{tabular}{lccccc}
\hline \multirow{2}{*}{ Employment } & \multicolumn{5}{c}{ Alcohol consumption $^{1}$} \\
\cline { 2 - 5 } & Never & Former & Current & Total & N \\
\hline None & 76 & 14 & 10 & 100 & 152 \\
Unpaid activities & 81 & 7 & 12 & 100 & 182 \\
Self-employed & 67 & 26 & 7 & 100 & 328 \\
Paid employment/activities & 65 & 20 & 14 & 100 & 116 \\
Total & 72 & 18 & 10 & & 778 \\
\hline
\end{tabular}

${ }^{1}$ Never=never tasted alcohol; former $=$ have tasted alcohol, but not consumed any during last 12 months; current $=$ have used alcohol during last 12 months 
Brook, Kissy Road, and Lower Bombay Street. It is a major transition point, as it is the landing point for most of the small traditional boats that go along the coast and on the rivers leading upcountry. The worst living condition in 'Magazine' is on the slope down towards Destruction Bay (i.e. the sea). This slope is steep and lined with small creeks, which are usually filled with garbage and pollution from inhabitants living further up in the city. Particularly in the rainy season the area gets immensely humid and dirty.

Most of those who have made this part of 'Magazine' their home are young men between 17 and 25 years-old, who have come to Freetown quite recently. They dwell in informal structures made out of plastic and other kinds of used material, or they simply sleep on the street. Life in the 'Magazine' is hard, and many of the young boys and men in this area have developed a lifestyle of alcohol and drug use. Some income is earned by carrying goods for arriving passengers from the boats, and the daily income varies between 1,000 and 4,000 Leones. ${ }^{4}$ Most days, the boys involved in this business are lucky if they make more than 2,000 Leones. Some also make some money by sweeping the streets for traders; others sell palm wine or marijuana. From the interviews and focus group sessions, we were able to construct the following time schedule of an ordinary day for an ordinary boy in the 'Magazine'.

His day starts at $6 \mathrm{am}$, when he wakes up and looks for work. Breakfast is not an option. If he is lucky, he will make some money as a carrier or have an arrangement with a trader to sweep his or her part of the street. At around noon, this work is over - the streets are swept and no more boats are arriving. He will then head for the beach in order to wash himself before buying something to eat, and thereafter he will go to one of the many informal shacks in the 'Magazine' to drink palm wine or smoke marijuana. Alternatively he may have a small business selling palm wine and marijuana, which, on a good day, may earn him an additional 2,500 Leones. Around 6 pm, however, these activities are also over, as few people venture into this part of the 'Magazine' after dark. Thus, for the rest of the night the boys hang around in their informal meeting places, using what little money they have left on some food and more palm wine and marijuana. This is their life, seven days a week. Few things change in this part of Freetown.

The majority of the boys interviewed had come to Freetown in search of formal employment and education. Unable to find either they continued to stay at the place where they first entered Freetown. Their lives are difficult: they see very few opportunities, and palm wine and marijuana become their only comfort. As most of them either live alone or with friends, they are also beyond the social control and support of their families and communities. The feeling of permanent exclusion and lack of hope for the future that these boys express is immense, and hanging around with them one essentially gets the feeling that they are just waiting for something to happen. Should the ghost of civil war once more return to Sierra Leone, they boys and young men that we encountered in the 'Magazine' and in Sawa Ground, in and around Lumley Street and Regent Street, and in so many other palm wine shacks elsewhere would likely join anybody who promised them a better life in return for their services.

The men and women who hang around at Sawa Grounds in Victoria Park represent a different, but in many ways similar segment of the population. Sawa Grounds is by and large a recreational area. People do not live or sleep there, but it is a place where many spend most of their days, coming to drink palm wine and omoly (the locally produced gin) and to smoke marijuana.

Victoria Park was originally established as the 'green lung' and major recreational area of Central Freetown. It no longer resembles the beautiful park that it once may have been;

${ }^{4} 1,000$ Leones $=0.36$ USD $($ October 2004). 
now it is mainly a market and a trading centre. Sawa Grounds is in the middle of Victoria Park. Originally established by traders, the stalls were abandoned once business went sour. This part of Victoria Park has now been completely taken over by people selling palm wine, snacks, food, and other kinds of drinks (mainly soft drinks and omoly) and drugs (mainly marijuana). The men we interviewed in Sawa Grounds were all former combatants; some had belonged to the militia known as the Westside Boys and had spent nearly four years in jail, in Pademba Road prison, from where they had only recently been released. All these men and their women showed signs of having been through terrible ordeals during the war, and as a fieldwork location, Sawa Grounds was different from the good-spirited conversations we had with the boys in the 'Magazine'. The atmosphere in Sawa Grounds was much more tense, and fighting and violent behaviour happened frequently. The air was thick with the smoke of marijuana, and the mud stank of urine and sweat. In the suffocating heat under the plastic roof over the stalls, there was a sense of danger present that we never experienced in the 'Magazine', or elsewhere in Freetown or in Mile 91 or Bo. That said, the stories told by the people frequenting Sawa Grounds were by and large the same as we heard elsewhere; tales of missed opportunities and expressions of social exclusion, marginalisation, and the little comfort to be found in drinks and drugs.

\section{Bo-traditional values vs. diamond mining}

Bo is the heart of the area of Sierra Leone that is dominated by the Mende people. Alcohol and drugs are used by certain segments of the youth and males here, but abuse is less openly than in Freetown. Palm wine is consumed in rather large quantities in informal bars, but you have to look for them in order to find them; it is similar with the drug scene. People told us that ex-combatants and the young men driving motorcycle taxis were notorious drug users. According to popular discourse, most of them were 'high' on drugs, particularly at night. Nevertheless, drugs were simply not a subject of conversation in Bo, and the timeframe of our study did not give us the time necessary to gain the trust of some of the young men.

However, the traditional values evident in Bo are also counterweighted by the influence of the diamond mining, located nearby. Bo is situated close to the major axis of the distribution of diamonds in Sierra Leone, the Sewa River Basin. Tributors dig gravel from swamps and streambeds during the dry season, and then siege the gravel before the rainy season floods overtake makeshift work camps. Mining diamonds is a hard way to make a living, and, although Sierra Leone is rich in diamonds, tributors sometimes still have to dig for a considerable amount of time before they find anything. In the meantime, they have to live on their 'supporter' (employer).

The arrangement between a supporter and his tributors may vary in accordance with its duration, whether there are communal or family ties between them, and last but not least, the reputation of the tributor. According to our informants, the standard arrangement is that the supporter provides each of his tributors with 300 Leones and a cup of rice per day. Sometimes they are also given some tools, and shot-guns and cartridges to hunt for food. When there is profit, the tributors split between them a two-fifth share of the local price of a season's catch of diamonds. However, of this profit each individual tributor must usually pay back to the supporter what has been provided to them during the season, i.e. the cost of the rice and the 300 Leones per. The relationship therefore resembles bonded labour arrangements. The economic circle of the miner is almost always one of rise and fall.

Many tributes believe that diamonds make their way through the earth, working their way upward carrying with them their finder's name. The hardship is made tolerable by consuming palm wine - which most of the tributes we talked to also consider food - and by using marijuana and to certain extent hard drugs such as crack cocaine. Music, drink, and recreational drugs help sustain the dream about the diamond.

In order to understand the world of the tributes, it is important to recognise that this 
is a man's world. There are very few women living with the miners. One explanation for the lack of women is taboos connected to diamond mining: Women living with diamond miners are considered likely to reduce their luck (hajia), and they are therefore excluded from the tributors' living area. This belief reflects the connection between current ideas about diamonds and traditional taboos about sexual activity, gender mixing, and hunting (Boeck 1999). The fact that these men live without a family, and that many come from all over Sierra Leone, contributes to the establishment of a certain subculture built on wishful ideas about diamonds maintained through drinking and drug-use. Traditional rural authorities have little or no control over this group: detached from traditional norms and their native society, this group of men is negotiating its own version of modernity. This is in our view, the main explanation for why rural communities in the diamond areas have a completely different pattern of alcohol and drug consumption than rural communities that are not exposed to diamonds and similar resources.

\section{DISCUSSION}

Regardless of how one looks at the causes and consequences of the war in Sierra Leone, it must be characterised as a watershed in the history of the country. During the war, alcohol, and drugs were often used as a boost to masculinity and as a rite of passage into the army or rebel movements. The rebels of the RUF, the soldiers in the army, and the militiamen of the Kamajoi all used alcohol and drugs in one form or another (Amnesty International 1995; Musah 2000; Bangura 2004; Keen 2005). Young men caught up in a situation like the one prevailing in the Sierra Leone civil war can easily come to internalise a certain pattern of alcohol and drug consumption. This could lead to the conclusion that an increased level of alcohol and drug abuse should be observable in postwar Sierra Leone.
This is, however, not the case. As this study reveals, the pattern of alcohol and drug consumption in Sierra Leone is the same as we find in other African countries that has never experienced civil war (Bryceson 2002). The majority of the population do not drink very much or use drugs at all, but there is a small minority that are frequent drinkers and use drugs. Some people drink a lot and use a lot of drugs, and some of this consumption is quite open; this is particularly the case in parts of Freetown. Such observations may easily lead us to think that the problem is larger than it actually is in Sierra Leone.

There are many reasons why people drink and take drugs, and why consumption patterns change. However, we believe that in Sierra Leone, as in any other country, such patterns are affected by urban migration and mobility (e.g. to Freetown), new income opportunities (e.g. the diamond areas around Bo), and by extreme social stress (e.g. the civil war). These three factors, alone or in combination, point to the probability of increased consumption of alcohol and drugs. Conversely, our material shows that being a woman, a Muslim, and living in a traditional community significantly reduce the probability of drinking or taking drugs. Importantly, what separate a traditional community from a non-traditional community are not necessarily the urban-rural distinction, but the degree to which the community is exposed to high levels of migration and/or new income opportunities. This is illustrated in our study by the cases of the villages around Mile 91 and Bo town.

\section{CONCLUSION}

Most people in Sierra Leone do not drink or use drugs. The civil war has therefore not affected the traditional African drinking pattern. This is quite remarkable given the frequent report of alcohol and drug abuse during the war. Heavy drinking and the use of drugs are therefore a relatively marginal phenomenon in Sierra Leone. However, as we have seen, there is also a tendency to some 
polarisation as there is minority that frequently drinks and use quite a lot of drugs. Those that do are, for most part, relatively young people that either live in a more cosmopolitan urban setting (e.g. Freetown) or in a rural setting where non-agriculture income opportunities are available (e.g. the diamond areas). Both these areas have experienced high levels of migration and mobility, cutting people off from the bonds of traditional society.

The war obviously also explains why some people are part of a subculture that has internalised alcohol and drug use as a way of life. The former combatants we interviewed at Sawa Grounds in Freetown vividly illustrate the latter scenario. The visibility of some of these user groups, particularly in Freetown, may in fact lead to the conclusion that the problem with alcohol and drugs is larger than it actually is in Sierra Leone. However, for those that drink too much or take drugs, or live in conditions such as 'the boys' in the Magazine, or have past experiences like the former Westside Boys, the consumption of alcohol and drugs clearly contribute to their problems and misery.

Less drinking and drug use will not necessarily solve their problems or give them access to employment and education, but it may at least increase their opportunity to take responsibility for their own lives, both as individuals and collective groups. This is important because, given the current state of affairs in Sierra Leone, neither the state nor other implementing agencies do very much for these people.

Finally, it is important to note that, in contemporary Sierra Leone, what we in fact see is the three-faces of Bacchus: the face of joy, the face of misery, and the face of pragmatism. First, whether one likes it or not, alcohol and drugs do offer some people some comfort and joy. This may be of importance in itself, particularly for people whose life otherwise has so little consolation. In some ways, it is a coping strategy: for some it may work, but for others it just leads to more misery. This suggests that the problem of alcohol and drugs in Sierra Leone must be addressed with pragmatism. Although alcohol and drug use is a problem for certain parts of the population, for others - such as the many female kiosk and street vendors of palm wine - it is an important income-generating activity whose loss would be extremely hard for them to bear. Suggesting that in this case, as in any other case, the principle for policy intervention must be the maxims of 'do no harm'.

\section{REFERENCES}

Abdullah, I. (1998). Bush path to destruction: the origins and character of the Revolutionary United Front (RUF/SL). Journal of Modern African Studies, 36(2), 305-235.

Abdullah, I. and Muana, P. (1998). The Revolutionary United Front of Sierra Leone. In C. Clapham (ed.), African Guerrillas, Oxford: James Currey, pp. 172-193.

Amnesty International (1995) Sierra Leone: Human Rights Abuses in a War Against Civilians, London: Amnesty International.

Anderson, K. H. and Mitchell, J. M. (1992). Effects of military experience on mental health problems and work behaviour. Medical Care, 30(6), 554-563.

Bangura, Y. (2004). Understanding the political and cultural dynamics of the Sierra Leone war: a critique of Paul Richards' Fighting of the Rain Forest. In Ibrahim Abdullah (ed.), Between Democracy and Terror: the Sierra Leone Civil War. Dakar: CODESRIA, pp. 13-40.

Boeck, F. (1999). Domesticating diamonds and dollars: identity, expenditure and sharing in Southwestern Zaire (1984-1997). In Birgit Meyer and Peter Geschiere (eds.), Globalization and Identity: Dialectics of Flow and Closure. Oxford: Blackwell, pp. 177-209.

Bryceson, D. F. (ed.) (2002). Alcohol in Africa: Mixing Business, Pleasure and Politics, Portsmouth: Heinemann. 
Bøås, M. (2001). Liberia and Sierra Leone - dead ringers? The logic of neopatrimonial rule, Third World Quarterly, 22(5) 697-723.

Bøås; M. (2007). Marginalized youth. In M. Bøås and K. C. Dunn (eds.), African Guerrillas: Raging Against the Machine. Boulder: Lynne Rienner, pp. 39-53.

Bøås, M. and Hatløy, A. (2005). Alcohol and Drug Consumption in Post War Sierra Leone - an Exploration. Oslo: FORUT Campaign for Development and Solidarity.

Bøås, M. and Hatløy, A. (2006). Living in a Material World: Children and Youth in Alluvial Diamond Mining in Kono District, Sierra Leone, Oslo: Fafo (Faforeport no. 515).

Horton, D. (1943). The functions of alcohol in primitive societies: a cross-cultural study. Quarterly Journal of Studies on Alcohol, 4, 199-320.

Jensen, S. B. (2002). Mental Health and Substance Abuse in Post Conflict Sierra Leone, Freetown: WHO Sierra Leone.
Keen, D. (2005). Conflict \& Collusion in Sierra Leone, Oxford: James Currey.

Mandelbaum, D. G. (1965) Alcohol and culture. Current Anthropology, 6(3), 281288.

Martin, J. K, Roman, P. M. and Blum, T. C. (1996). Job stress, drinking networks and social support at work: a comprehensive model of employees' problems of drinking behaviours. The Sociological Quarterly, 37(4), 579-599.

Musah, A. (2000). A country under siege: state decay and corporate military intervention in Sierra Leone. In A. Musah and J. K. Fayemi (eds.), Mercenaries: An African Security Dilemma. London: Pluto Press, pp. 76-116.

Partanen, J. (1988). Abstinence in Africa. In J. Maula, M. Lindblad and C. Tigerstedt (eds), Alcohol in Developing Countries. Helsinki: Nordic Council for Alcohol and Drug Research, pp. 70-85. 